Editorial

\title{
Special Issue Editorial: Green Buildings and Indoor Air Quality
}

\author{
Dusan Licina \\ Human-Oriented Built Environment Lab, School for Architecture, Civil, and Environmental Engineering, \\ École Polytechnique Fédérale de Lausanne, 1015 Lausanne, Switzerland; dusan.licina@epfl.ch
}

Received: 9 April 2020; Accepted: 21 April 2020; Published: 27 April 2020

Since the inception of the first green certification scheme several decades ago, expectations for high-performance buildings have been evolving. To date, there are more than 200 different green building certification programs around the globe, with estimates of at least 1 million certified projects across different building types. While the green building industry has a long-standing history of attention to human health (e.g., tobacco control, toxic exposure), there has been a recent shift in the prioritization of this issue relative to others, with a new emphasis on features that explicitly promote the human experience of building occupants.

In recognition of this emphasis shift, The Atmosphere Special Issue "Green Buildings and Indoor Air Quality" aimed to showcase the most recent findings related to air quality investigations in green buildings. The specific topic covered in seven original papers accepted for publication can be divided onto two groups: (1) three studies that investigated the effectiveness of air quality management strategies through the low-emission materials, green walls, ventilation, and airflow control; and (2) four studies that focused on enhancing knowledge on indoor air quality, comfort, and energy performance in green-certified dwellings, newly constructed public housing, and low-energy or high-performing schools.

Among papers studying the effectiveness of different air quality management practices, Babich et al. [1] examined the trade-offs between new material off-gassing levels and potential energy savings in ventilation. The cost-benefit analysis for an exemplary residential building showed that selecting less- or low-polluting materials increases the initial capital cost, but in the long run offers economic benefits, owing to energetic savings in reduced ventilation rates without compromising indoor air quality. According to Petit et al. [2], an ability to enhance indoor air quality without compromising energetic performance of buildings can be also achieved by active green walls. It was found that two types of commonly grown plants can be used in active green walls to reduce the concentration of ambient nitrogen dioxide $\left(\mathrm{NO}_{2}\right)$. While this study offered evidence that active green walls are promising technology that can effectively filter $\mathrm{NO}_{2}$, it also recommended that more in situ efforts should be directed towards investigating practical removal rates and plant health effects from prolonged exposure to air pollution. Furthermore, the influence of indoor airflow in a solar passive building on the indoor air quality and thermal comfort levels was numerically investigated by Conceição et al. [3]. The results show that it is possible to determine an optimal air change rate that does not compromise thermal comfort and indoor air quality in winter and summer conditions, which can also result in reduced building energy use.

The second group of papers offered useful insights about influence of energy retrofit and green-certification on indoor air quality in dwellings, indoor air quality and comfort monitoring in low-energy high-performing schools, and energy consumption. As part of the first large-scale field campaign examining indoor air quality and energy status in Swiss energy-efficient and green dwellings [4,5], Yang et al. [6], compared the radon levels in 650 green-certified and energy-renovated 
dwellings and analyzed the building characteristics responsible of radon accumulation. It was found that the newly green-certified dwellings with embedded mechanical ventilation had significantly lower radon levels than energy-renovated dwellings. Thermal retrofitting of windows, roofs, exterior walls, and floors were associated with a higher radon level. The energy renovation itself was responsible for $20 \%$ increase of indoor radon. Another research contribution focused on quantifying the effects of redeveloping public housing developments into new buildings with improved energy performance and indoor environmental quality [7]. The study documents that economic savings are possible with affordable green housing in Boston and that significant energy consumption savings are possible from electricity, gas, and water consumption by redeveloping an existing public housing to LEED certification. Another two research studies investigated frequently encountered issues with indoor air quality in schools. One of them focused on deployment of a microfluidic device for detection of formaldehyde concentrations coupled with a fluorescence detection system [8]. The second study [9] examined indoor environmental quality in five schools which included three high-performance schools, one recently renovated school, and one conventional school. Interestingly, the three high-performance schools did not have measurably better quality of indoor environment than the renovated and conventional schools, nor were they perceived as better, based on the satisfaction survey. The results point in direction of the pressing need of high-performance design standards to put stronger emphasis on reducing health-related pollutants in schools.

Buildings providing an intentional combination of enhanced indoor air quality and human performance are increasingly recognized as better assets as they come to define leadership in the real-estate industry. This Special Issue supports the ongoing revolution in the real-estate industry as it corroborates the evidence that buildings can do more to support higher indoor air quality, human performance, and experience.

Funding: This research received no external funding.

Acknowledgments: Thanks are expressed to the authors for their contributions, Jose Guillermo Cedeno Laurent for helping in co-editing this special issue, the reviewers for their comments and the editorial office for the support in publishing this issue.

Conflicts of Interest: The author of this editorial declares no conflict of interest.

\section{References}

1. Babich, F.; Demanega, I.; Avella, F.; Belleri, A. Low Polluting Building Materials and Ventilation for Good Air Quality in Residential Buildings: A Cost-Benefit Study. Atmosphere 2020, 11, 102. [CrossRef]

2. Pettit, T.; Irga, P.J.; Surawski, N.C.; Torpy, F.R. An Assessment of the Suitability of Active Green Walls for NO2 Reduction in Green Buildings Using a Closed-Loop Flow Reactor. Atmosphere 2019, 10, 801. [CrossRef]

3. Conceição, E.; Gomes, J.; Awbi, H. Influence of the Airflow in a Solar Passive Building on the Indoor Air Quality and Thermal Comfort Levels. Atmosphere 2019, 10, 766. [CrossRef]

4. Yang, S.; Goyette Pernot, J.; Hare Jörin, C.; Niculita-Hirzel, H.; Perret, V.; Licina, D. Energy, indoor air quality, occupant behavior, self-reported symptoms and satisfaction in energy-efficient dwellings in Switzerland. Build. Environ. 2020, 171, 106618. [CrossRef]

5. Yang, S.; Perret, V.; Niculita-Hirzel, H.; Hager Jörin, C.; Goyette Pernot, J.; Licina, D. Volatile organic compounds in 169 energy-efficient dwellings in Switzerland. Indoor Air 2020. [CrossRef] [PubMed]

6. Yang, S.; Goyette Pernot, J.; Hager Jörin, C.; Niculita-Hirzel, H.; Perret, V.; Licina, D. Radon Investigation in 650 Energy Efficient Dwellings in Western Switzerland: Impact of Energy Renovation and Building Characteristics. Atmosphere 2019, 10, 777. [CrossRef]

7. Brod, M.; Cedeño Laurent, J.G.; Kane, J.; Colton, M.D.; Gabel, C.; Adamkiewicz, G. Greener and Leaner: Lower Energy and Water Consumption, and Reduced Work Orders, in Newly Constructed Boston Public Housing. Atmosphere 2020, 11, 329. [CrossRef] 
8. Trocquet, C.; Bernhardt, P.; Guglielmino, M.; Malandain, I.; Liaud, C.; Englaro, S.; Le Calvé, S. Near Real-Time Monitoring of Formaldehyde in a Low-Energy School Building. Atmosphere 2019, 10, 763. [CrossRef]

9. Oldham, E.; Kim, H. IEQ Field Investigation in High-Performance, Urban Elementary Schools. Atmosphere 2020, 11, 81. [CrossRef] 